\title{
Personal Positioning Method of Digital Community Monitoring System
}

\author{
Hongdi Ke ${ }^{1, a^{*}}$ and Lu Ming ${ }^{1, b}$ \\ 1 Department of Technology,Jilin Business and Technology College,Changchun 130507,China \\ a13661033@qq.com, b975579008@qq.com
}

Keywords: Digital Medical Care; Wireless Network; RSSI; Maximum Likelihood Estimation Algorithm; Trilateral-weighted Centroid localization algorithm

\begin{abstract}
Wireless network can be used to digital community monitoring system, personal positioning method is the important component of the digital community monitoring system. On the basis of studying the traditional personal positioning algorithms, we proposed a trilateral-weighted centroid localization algorithm. On a wireless network hardware platform we validated that this algorithm had Higher precision than traditional algorithms.
\end{abstract}

\section{Introduction}

China had already entered old-age society, by 2014, the Old-age people more than 60 years account for nearly 15.5 per cent of the population, which is about 210 million[1]. The development of community health service level represents the progress of a social level, correspondence the new medical technology such as modern network technology, communication technology, control technology and some medical equipment terminals, realize medical service and health care services, care services, emergency service, health education inside a family, build a digital community monitoring system is the the future of endowment trend[2,4]. Personal positioning method is the important component of the digital community monitoring system. Personal positioning method can carry on position location and position display for the aged at real time. The crucial of the Personal positioning method is to understand the health-status of the aged, and rescue them timely when they are in danger[5].

The topic researches on the key technologies of digital community monitoring system. Wireless network and embedded technology have been used in the system. On the basis of studying the traditional personal positioning algorithms, we proposed a trilateral-weighted centroid localization algorithm. We used trilateral-weighted centroid localization algorithm and trilateral-weighted centroid localization maximum likelihood estimation algorithm in Personal Positioning study. The results of test verify that the trilateral-weighted centroid localization algorithm had higher precision than traditional algorithms.

\section{Positioning Algorithms}

The existing wireless sensor network localization algorithms can be divided into 2 categorys: Range-based positioning algorithms and Range-free positioning algorithms[3,6]. Range-based positioning algorithms include RSSI, TOA, RTOF, TDOA, PDOA, AOA, NFEM[7]. Range-based positioning algorithms are rarely used in the existing positioning systems. Range-free positioning algorithms include Trilateration, Min-max, Triangulation, Maximum Likelihood Estimation.

Maximum Likelihood Estimation. Wireless network includes two kinds of nodes, one kind is the nodes know their position, known as the reference node; Another kind is needed by calculating for the location of the node, called the blind node. According to the distance between reference node and blind node, we can calculate blind node's coordinate[3,8]. Shown as Fig. 1, n known reference nodes' coordinates are $(\mathrm{xi}, \mathrm{yi})(1 \leqslant \mathrm{i} \leqslant \mathrm{n}$, I is an integer), blind node's (D) coordinates is $(\mathrm{x}, \mathrm{y})$, there is:

$$
\left(x-x_{i}\right)^{2}+\left(y-y_{i}\right)^{2}=d_{i}^{2}
$$


blind node $\mathrm{D}$ can be obtained by the method of least squares,

$$
\begin{aligned}
& X=\left(A^{T} A\right)^{-1} A^{T} b \\
& X=\left[\begin{array}{l}
x \\
y
\end{array}\right] \\
& A=\left[\begin{array}{cc}
2\left(x_{1}-x_{n}\right) & 2\left(y_{1}-y_{n}\right) \\
\vdots & \vdots \\
2\left(x_{n-1}-x_{n}\right) & 2\left(y_{n-1}-y_{n}\right)
\end{array}\right] \\
& b=\left[\begin{array}{c}
x_{1}^{2}-x_{n}^{2}+y_{1}^{2}-y_{n}^{2}+d_{n}^{2}-d_{1}^{2} \\
\vdots \\
x_{n-1}^{2}-x_{n}^{2}+y_{n-1}^{2}-y_{n}^{2}+d_{n}^{2}-d_{n-1}^{2}
\end{array}\right]
\end{aligned}
$$

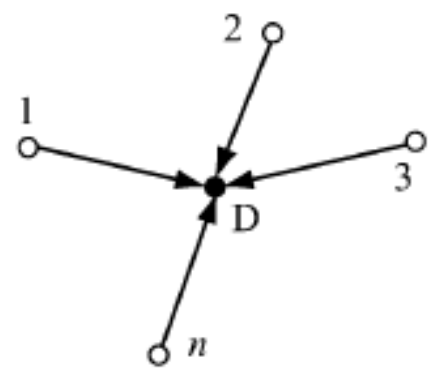

Figure 1. Maximum likelihood estimation method

Trilateral-weighted Centroid Localization Algorithm. 3 known reference nodes A, B, C, blind node and the reference node distances are RA, RB, RC, centered on A, B, C, RA and RB, RC for the radius of circle. The intersection of three circle area, intersection of two circles set to $\mathrm{O} 1, \mathrm{O} 2, \mathrm{O} 3$ coordinates to satisfy the following equations[3,9]:

$$
\begin{aligned}
& \left\{\begin{array}{l}
\left(x_{01}-x_{B}\right)^{2}+\left(y_{01}-y_{B}\right)^{2}=R_{B}^{2} \\
\left(x_{01}-x_{C}\right)^{2}+\left(y_{01}-y_{C}\right)^{2}=R_{C}^{2} \\
\left(x_{01}-x_{A}\right)^{2}+\left(y_{01}-y_{A}\right)^{2} \leq R_{A}^{2}
\end{array}\right. \\
& \left\{\begin{array}{l}
\left(x_{01}-x_{B}\right)^{2}+\left(y_{01}-y_{B}\right)^{2}=R_{B}^{2} \\
\left(x_{01}-x_{C}\right)^{2}+\left(y_{01}-y_{C}\right)^{2}=R_{C}^{2} \\
\left(x_{01}-x_{A}\right)^{2}+\left(y_{01}-y_{A}\right)^{2} \leq R_{A}^{2}
\end{array}\right. \\
& \left\{\begin{array}{l}
\left(x_{01}-x_{B}\right)^{2}+\left(y_{01}-y_{B}\right)^{2}=R_{B}^{2} \\
\left(x_{01}-x_{C}\right)^{2}+\left(y_{01}-y_{C}\right)^{2}=R_{C}^{2} \\
\left(x_{01}-x_{A}\right)^{2}+\left(y_{01}-y_{A}\right)^{2} \leq R_{A}^{2}
\end{array}\right.
\end{aligned}
$$


Obtained intersection $\mathrm{O} 1, \mathrm{O} 2, \mathrm{O} 3$ coordinates by equations(7) (8) (9),composed triangle by $\mathrm{O} 1$, $\mathrm{O} 2, \mathrm{O} 3$ as verticles. In $\Delta \mathrm{O}_{1} \mathrm{O}_{2} \mathrm{O}_{3}$,we considered the weighted value as follow: for example, first, reference node $\mathrm{O} 1$ is made up $\odot \mathrm{B}$ and $\odot \mathrm{C}$ intersection, so the weighted value have $\mathrm{RB}$ and $\mathrm{RC}$, secondly, blind node $\mathrm{O}$ is made up of $\mathrm{OA}, \mathrm{OB}$ and $\mathrm{OC}$, reference node $\mathrm{O} 1$ should be considered in the middle of the weighted variables influence of RA; Finally consider the distance between blind node and reference node is inversely proportional to the weighted value. So, the weighted value of $\mathrm{O} 1$ is: $\frac{1}{\mathbb{R}_{B}+R_{C}}+\frac{1}{\mathbb{R}_{\mathbb{A}}^{n}}$, the weighted value of $\mathrm{O} 2$ is: $\frac{1}{\mathbb{R}_{A}+R_{C}}+\frac{1}{\mathbb{R}_{B}}$, the weighted value of $\mathrm{O} 3$ is: $\frac{1}{\mathbb{R}_{A}+R_{B}}+\frac{1}{\mathbb{R}_{C}^{n}}$, we obtained blind node's coordinate $\mathrm{O}(\mathrm{x}, \mathrm{y})$ :

$$
\begin{aligned}
& \mathrm{x}_{\mathrm{i}}=\frac{\mathrm{x}_{01} \cdot\left(\frac{1}{\mathrm{R}_{\mathrm{B}}+\mathrm{R}_{\mathrm{C}}}+\frac{1}{\mathrm{R}_{\mathrm{A}}^{\mathrm{n}}}\right)+\mathrm{x}_{02} \cdot\left(\frac{1}{\mathrm{R}_{\mathrm{A}}+\mathrm{R}_{\mathrm{C}}}+\frac{1}{\mathrm{R}_{\mathrm{E}}}\right)+\mathrm{x}_{0 \mathrm{~B}} \cdot\left(\frac{1}{\mathrm{R}_{\mathrm{A}}+\mathrm{R}_{\mathrm{B}}}+\frac{1}{\mathrm{R}_{\mathrm{Z}}}\right)}{\left(\frac{1}{\mathrm{R}_{\mathrm{A}}^{\mathrm{n}}}+\frac{1}{\mathrm{R}_{\mathrm{B}}}+\frac{1}{\mathrm{R}_{\mathrm{C}} \mathrm{Z}}\right)+\left(\frac{1}{\mathrm{R}_{\mathrm{A}}+\mathrm{R}_{\mathrm{B}}}+\frac{1}{\mathrm{R}_{\mathrm{B}}+\mathrm{R}_{\mathrm{C}}}+\frac{1}{\mathrm{R}_{\mathrm{A}}+\mathrm{R}_{\mathrm{C}}}\right)} \\
& y_{i}=\frac{y_{01} \cdot\left(\frac{1}{R_{B}+R_{C}}+\frac{1}{R_{A}^{n}}\right)+y_{01} \cdot\left(\frac{1}{R_{A}+R_{C}}+\frac{1}{R_{E}}\right)+y_{01} \cdot\left(\frac{1}{R_{A}+R_{B}}+\frac{1}{R_{C}}\right)}{\left(\frac{1}{R_{A}^{n}}+\frac{1}{R_{B}}+\frac{1}{R_{C}}\right)+\left(\frac{1}{R_{A}+R_{B}}+\frac{1}{R_{B}+R_{C}}+\frac{1}{R_{A}+R_{C}}\right)}
\end{aligned}
$$

\section{Test Anlysis}

Digital Community Monitoring System is made up for parts: reference node, blind node, gateway node and PC. We chose 18 reference nodes and 1 blind node, in an empty area, set 18 reference nodes to two rows, formed to $40 \mathrm{~m}$ long, for the positioning area of $5 \mathrm{~m}$ wide, and correction coefficient $\mathrm{n}=$ 3 , the whole test steps as follows[10]:

(1) Open the power of the blind node, Blind node initialize, and then send its' ID information;

(2) Reference node receive RSSI;

(3) 18 reference nodes send RSSI to PC;

(4) Matlab simulates two Algorithms.

In 8 region obtained 8 test results.

\begin{tabular}{|c|c|c|c|c|}
\hline $\begin{array}{l}\text { Reference } \\
\operatorname{node}\left(\mathrm{X}_{\mathrm{i}}, \mathrm{Y}_{\mathrm{i}}\right)\end{array}$ & $\begin{array}{l}(0,10), \\
(5,10),(0,5)\end{array}$ & $\begin{array}{l}(5,5), \\
(5,10),(10,5)\end{array}$ & $\begin{array}{l}(15,5), \\
(15,10),(10,5)\end{array}$ & $\begin{array}{l}(20,10), \\
(15,10),(20,5)\end{array}$ \\
\hline Blind node ID & $0 x d 1$ & $0 x d 1$ & $0 \mathrm{xd} 1$ & $0 x d 1$ \\
\hline RSSI & $0 \times 32,0 \times 33,0 \times 34$ & $0 \times 2 c, 0 \times 34.0 \times 34$ & $0 \times 2 f, 0 \times 33,0 \times 36$ & $0 \times 2 \mathrm{~d}, 0 \times 32,0 \times 35$ \\
\hline $\begin{array}{l}\text { Reference } \\
\operatorname{node}\left(\mathrm{X}_{\mathrm{i}}, \mathrm{Y}_{\mathrm{i}}\right)\end{array}$ & $\begin{array}{l}(20,5), \\
(25,5),(20,10)\end{array}$ & $\begin{array}{l}(30,10), \\
(25,10),(30,5)\end{array}$ & $\begin{array}{l}(35,5), \\
(35,5),(30,10)\end{array}$ & $\begin{array}{l}(40,10), \\
(35,10),(40,5)\end{array}$ \\
\hline Blind node ID & $0 x d 1$ & $0 \mathrm{xd} 1$ & $0 x d 1$ & $0 x d 1$ \\
\hline RSSI & $0 \times 32,0 \times 33,0 \times 36$ & $0 \times 31,0 \times 33,0 \times 32$ & $0 \times 32,0 \times 35,0 \times 34$ & $0 \times 31,0 \times 33,0 \times 34$ \\
\hline
\end{tabular}

Table 1 High and low settings of predictor variables 


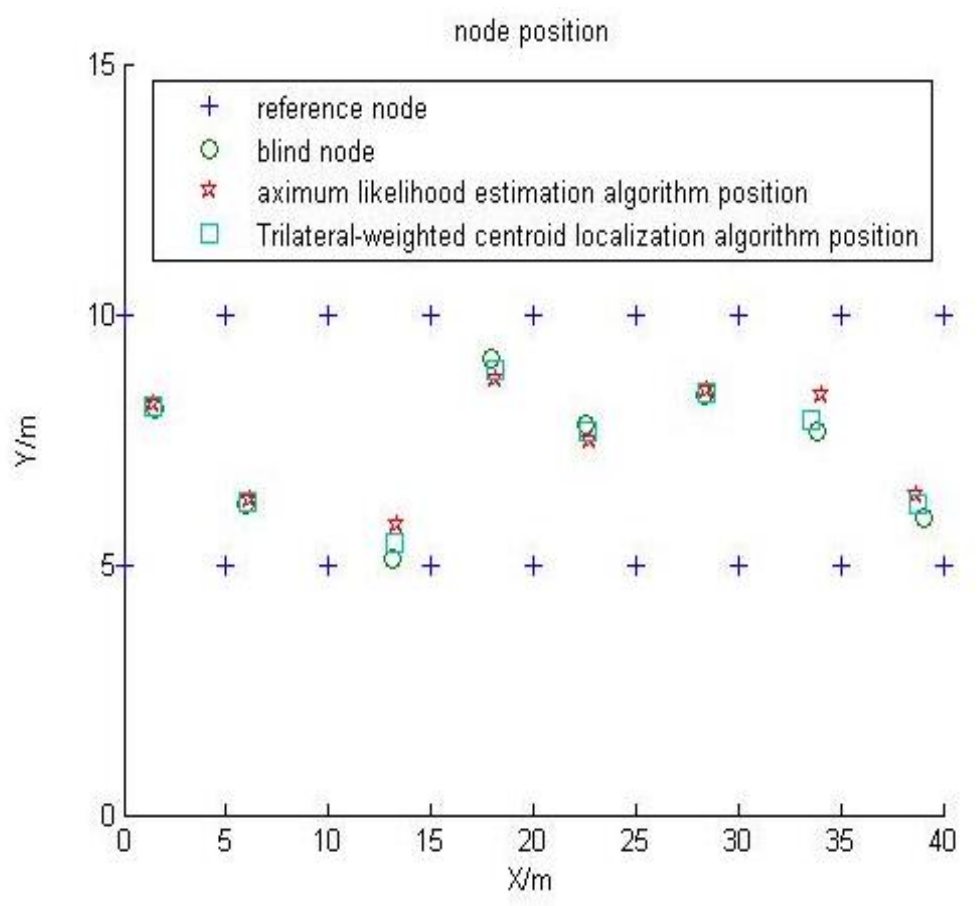

Figure 2. Matlab Simulate Result

Shown as Fig. 2, 18 reference nodes and 1 blind node, trilateral-weighted centroid localization algorithm has higher precision than maximum likelihood estimation algorithm.

\section{Summary}

In the topic, we proposed a trilateral-weighted centroid localization algorithm. We used trilateral-weighted centroid localization algorithm and maximum likelihood estimation algorithm in Digital Community Monitoring System . On a wireless network hardware platform we validated that this algorithm had higher precision than traditional algorithms.

\section{Acknowledgements}

The research conducted in this paper have been supported by the fund of Jilin Provincial Education department(No.2014438) and JiLin Business and Technology doctor fund(No.201626).

\section{References}

[1] W.X.Tai: Research and Design of Mine Personnel Location System Based no Zigbee Wireless Sensor Network((Ms, Taiyuan University of Technology, China 2013), p.23.

[2] W.Qian: The Research and Design of Wireless Position System Based on ZigBee((Ms, Shanghai Jiao Tong Universityy, China 2011), p.44.

[3] Hou Qizhen, Shi Bingxin and Liu Yanfan:.Computer Applications and Software, Vol.33. (2016).No.4, p134-137.

[4] Zhou.Wei: Research on Localization and Tracking Based on Wireless Sesor Networks((Ph.D., Chongqing Universityy, China 2011), p.65.

[5] Han Jianghong, Zhu Manquan,Ma Xuesen and Liu Huiping:Journal of Electronic Measurement and Instrument,Vol.27(2013).No.10,p937-942.

[6] Zheng Xueli, Fu Jingqi:Chinese Journal of Scientific Instrument,Vol.36(2015).No.5, 
P1177-1184.

[7] Ding L,Guan X W:Foreign Electronic Measurement Technology.Vol.12(2014).No.33,P67-73.

[8] Liu X M,Zhang Ch,Hu J Zh:Journal of Qingdao University of Science and Technology, Vol.2(2009).No30,P173-175.

[9] Sun Jichen,Li Chen xin:Journal of China University of Mining\&Technology, Vol.43(2014).No.6,P1127-1133.

[10] Information on http://www.ilovematlab.cn/forum.php. 